\title{
Editorial
}

\section{Aquatic ecosystem assessment and management}

\author{
Young-Seuk Park* \\ Department of Life and Nanopharmaceutical Sciences and Department of Biology, Kyung Hee University, Seoul 02447, \\ Republic of Korea
}

The Second Symposium of the Benthological Society of Asia (BSA) took place in Busan, Republic of Korea, June 5-7, 2014. We hosted more than 150 participants with two distinguished keynote speakers and more than 100 presentations. We exchanged professional ideas, fostered friendships and enjoyed beautiful scenes and culture in Busan, Korea. In the keynote lectures, Bob M. Hughes (Amnis Opes Institute, USA) shared his research on bioassessment in water resources management, in particular the use of macroinvertebrate assemblages for assessing ecological conditions across large regions. Jane M. Hughes (Griffith University, Australia) introduced her studies on molecular approaches to answering ecological and evolutionary questions.

The conference focused on Aquatic Ecosystem Assessment and Management: from Molecules to Communities with seven sessions. Along with two special sessions on assessment (Perspective of Riverine Biomonitoring and Benthic Macroinvertebrates in East Asia) and molecular biology (Use of Molecular Genetics in Studies of Ecology, Evolution and Taxonomy) and a workshop on taxonomy (Key to the Tropical Southeast Asian Aquatic Insects), we had five sessions broadly covering biological monitoring, conservation, management, systematics, biodiversity, community dynamics, and physiology and behaviour.

We should mention that this special issue of Aquatic Ecosystem Assessment and Management does not aim to present the best papers presented at the symposium. Many interesting papers were presented, but were not all included in this issue. The papers in this issue were selected based on the reviewers' recommendations, and were organized into three sections: Biological assessment, water quality and algal bloom, and biodiversity based on their topics.

\section{Biological assessment}

Bioassessment provides important information for ecosystem management. The current status of ecosystems could be assessed through various approaches based on

\footnotetext{
*Corresponding author: parkys@khu.ac.kr
}

hierarchical biological systems from molecules to communities. Biological responses at small-scale levels such as at the molecular level are rapid and provide accurate information (Ji and Park, 2012). However, the information is usually limited to the local scale, and fails to provide a comprehensive representation of the impacted ecosystems at larger scales. Meanwhile, the responses of communities at large-scale levels are slow and often imprecise, but their ecological relevance is high due to the accumulating effects of disturbances or stresses on the system. Therefore, a multi-level approach has recently been proposed for assessing ecological integrity (Schmutz et al., 2000).

Park et al. (2016) performed de novo transcriptome sequencing to produce a comprehensive expressed sequence tag resource for crabs Macrophthalmus japonicus. This species is abundant in estuaries and is a potential bioindicator reflecting aquatic sediment toxicity. Park et al. identified stress-response genes in M. japonicus exposed to the antifouling biocide irgarol. Qu et al. (2016) developed multiple biological indices using three groups of aquatic organisms - benthic algae, macroinvertebrates and fish for river health assessment. River health condition scores were assigned to five categories - critical, bad, fair, good and excellent. They recommended multiple biological indices to assess river health in river ecosystem management.

Species abundance distribution (SAD) describes the number of individuals encountered within a community for each species (Qu et al., 2008; Kim et al., 2016). Kim et al. (2016) investigated whether SAD patterns were seasonal and could be used to determine the impact of pollution. The pollution states were broadly divided into weak and strong pollution groups according to SAD models. The results confirmed that SADs with related parameters efficiently reflected ecological integrity.

\section{Water quality and algal bloom}

The water quality in freshwater systems is primarily dependent on material loading through hydrological processes within watersheds (Park et al., 2014; Wang 
et al., 2015). Eutrophication leads to algal blooms, causing the mortality of aquatic organisms from hypoxia and toxicity. Therefore, algal bloom control is fundamental in water quality management of freshwater ecosystems. To assess the effectiveness of aquaculture cessation for improving water quality, Ji et al. (2016) analysed the response of a phytoplankton community to the cessation of aquaculture in a Chinese lake. They found that nutrient concentrations did not change significantly after the cessation of aquaculture, whereas the phytoplankton community changed considerably. This was associated with the physical and biotic changes caused by the removal of aquaculture than with the variation in nutrient levels, indicating that phytoplankton monitoring is essential for assessing water quality.

Hong et al. (2016) presented a limnological assessment of the meteo-hydrological and physicochemical factors for summer cyanobacterial blooms in a regulated river system. Their results showed that rainfall, river flow, water temperature and nutrient concentration were the primary factors affecting cyanobacterial blooms in the study river system, suggesting that the successful control of cyanobacterial blooms requires integrated watershed management, accommodating the control and management of meteo-hydrological-physicochemical factors.

Kim (2016) introduced an innovative time-series model to predict the chlorophyll-a concentration in Korean rivers. A multiple process univariate model, which is an enhanced stochastic model, was developed to address the effects of distinct mechanisms associated with hydrometeorological factors and anthropogenic activities. The study demonstrated the strengths of the proposed model both in making predictions and in the parsimony of the model structure compared with traditional models.

\section{Biodiversity}

Biodiversity is threatened by various factors such as habitat loss and degradation, introductions of invasive alien species, overexploitation of natural resources, pollution and diseases and human-induced climate change (IUCN: http://https://www.iucn.org). Human activity is responsible for most of these factors. Among them, river damming is the anthropogenic factor that induces the most dramatic habitat loss and degradation in freshwater ecosystems (Park et al., 2003). Global warming has profound effects on the distribution and phenology of species, affecting biodiversity (Kwon et al., 2015), and it has already had observable effects on ecosystems worldwide, and an accelerated rate of global change is predicted in the future (Li et al., 2013, 2014, 2015).

Song et al. (2016) examined the effects of damming on the longitudinal distribution of fish in a Korean stream, using two computational methods: a self-organizing map (SOM) and spatial autocorrelation. Study areas were classified into four clusters in SOM, reflecting differences in the longitudinal distribution patterns of fish and the effects of the dam on fish community composition. Results of species turnover and spatial autocorrelation confirmed changes in the fish community near the dam, suggesting that the habitat alterations due to the dam construction have caused fragmentation of fish communities.

Chung et al. (2016) studied the effect of global warming on the thermal habitat suitability of endemic riverine fish and the relationship between change in species loss and altitude within a basin. The results showed that global warming is expected to negatively affect $2-20$ species in $4.3-35.5 \%$ of their thermal habitats from the $2060 \mathrm{~s}$ to 2080s. Their results implied that global warming would greatly affect the suitable habitats of endemic fish in Korean rivers, suggesting that biodiversity conservation efforts need to incorporate spatial heterogeneity in thermal regimes among river basins.

Phoretic association is a form of symbiosis between two species in which one organism transports the other. Boonsoong (2016) presented phoretic associations between larvae of Nanocladius asiaticus (Diptera, Chironomidae) and two species in the genus Gestroiella in streams of western Thailand. Gestroiella siamensis was used by chironomid larvae, and $N$. asiaticus larvae were associated symphoretically with nymphs of the damselfly Euphaea masoni.

\section{Benthological Society of Asia}

The BSA is a rapidly growing international scientific organization. It began as the Aquatic Entomological Societies in East Asia (AESEA) in 1998. The AESEA expanded and reformed as the BSA, covering a wider scope in benthological sciences in Asia. The BSA aims to: (1) lead development of benthological sciences academically and to contribute to the conservation and sustainable management of aquatic ecosystems in Asian countries; and (2) promote information exchange among members through regular and irregular meetings and communications (BSA website: http://www.benthosasia.org/).

The 3rd International Symposium of the BSA will be held on August 24-26, 2016, at the Far Eastern Federal University (Vladivostok, Russia) (Website http:// www.biosoil.ru/BSA2016). The main goal of the Symposium is to summarize knowledge in different branches of freshwater ecology in Asia, coordinate efforts in protection of freshwaters, and strengthen international cooperation in the Asian as well as global regions. You are warmly welcomed to the symposium and the BSA.

We are grateful to the reviewers for their helpful and constructive comments on the manuscripts presented in this special issue. We would like to thank Professor Régis Céréghino, former editor-in-chief of Annales de Limnologie - International Journal of Limnology, for consulting on this special issue.

The 2014 BSA Symposium was organized by the Local Organizing Committee: Tae-Soo Chon (BSA President and Symposium Chair, Pusan National University, Korea), Yeon Jae Bae (Korea University, 
Korea), Gea-Jae Joo (Pusan National University, Korea), Dong-Soo Kong (Kyonggi University, Korea), Sung-Cheol Koh (Korea Maritime and Ocean University, Korea), Inn-Sil Kwak (Chonnam National University, Korea), Young-Seuk Park (Kyung Hee University, Korea), Mi-Young Song (National Institute of Fisheries Science, Korea), Ho Young Suk (Yeungnam University, Korea), YongJin Won (Ewha Womans University, Korea), Kyung-Im Jung (secretary, Pusan National University, Korea) and Dong-Hwan Kim (secretary, Pusan National University, Korea). Finally, we acknowledge members of the Laboratory of Ecology and Behaviour Systems, Pusan National University, for their assistance during the symposium. The symposium would not have been successful without the efforts of all the participants. We are grateful to the participants and eagerly anticipate their contributions at the next BSA conference.

\section{References}

Boonsoong B., 2016. Phoretic associations between Nanocladius asiaticus (Diptera, Chironomidae) and its hosts Gestroiella (Heteroptera, Naucoridae) and Euphaea masoni (Odonata, Euphaeidae) in streams in Western Thailand. Ann. Limnol. Int. J. Lim., 52, 163-169.

Chung N., Kwon Y.-S., Li F., Bae M.-J., Chung E.G., Kim K., Hwang S.-J. and Park Y.-S., 2016. Basin specific effect of global warming on endemic riverine fish in Korea. Ann. Limnol. - Int. J. Lim., 52, 171-186.

Hong D.-G., Kim D.-K., Kim H.-W., Do Y., Lee H.Y. and Joo G.-J., 2016. Limnological assessment of the meteohydrological and physicochemical factors for summer cyanobacterial blooms in a regulated river system. Ann. Limnol. - Int. J. Lim., 52, 123-136.

Ji C.-W. and Park Y.-S., 2012. Characterising movement patterns of medaka (Oryzias latipes) in response to copper analysed by using a self-organising map. WIT Trans. Ecol. Environ., 162, 137-146.

Ji G., Xu L., Wang L., Xu Z., Dai X. and Zhang R., 2016. The response of phytoplankton in a subtropical lake to the cessation of aquaculture: a case study of Lake Dianshan, China. Ann. Limnol. - Int. J. Lim., 52, 109-121.

Kim D.-H., Song M.-Y. and Chon T.-S., 2016. Inferring pollution states based on community structure of benthic macroinvertebrates in streams. Ann. Limnol. - Int. J. Lim., 52, 91-108.
Kim S., 2016. A Multiple process univariate model for the prediction of Chlorophyll-a concentration in river systems. Ann. Limnol. - Int. J. Lim., 52, 137-150.

Kwon Y.-S., Bae M.-J., Hwang S.-J., Kim S.-H. and Park Y.-S., 2015. Predicting potential impacts of climate change on freshwater fish in Korea. Ecol. Inf., 29, 156-165.

Li F., Chung N., Bae M.-J., Kwon Y., Kwon T.-S. and Park Y.-S., 2013. Temperature change and macroinvertebrate biodiversity: assessments of organism vulnerability and potential distributions. Clim. Change, 119, 421-434.

Li F., Kwon Y.-S., Bae M.-J., Chung N., Kwon T.-S. and Park Y.-S., 2014. Potential impacts of global warming on the diversity and distribution of stream insects in South Korea. Conserv. Biol., 28, 498-508.

Li F., Tierno de Figueroa J.M., Lek S. and Park Y.-S., 2015. Continental drift and climate change drive instability in insect assemblages. Sci. Rep., 5, 11343. doi: 10.1038/ srep11343.

Park K., Nikapitiya C. and Kwak I.-S., 2016. Identification and expression of proteolysis-response genes for Macrophthalmus japonicus exposure to irgarol toxicity. Ann. Limnol. - Int. J. Lim., 52, 65-74.

Park Y.-S., Chang J., Lek S., Cao W. and Brosse S., 2003. Conservation strategies for endemic fish species threatened by the Three Gorges Dam. Conserv. Biol., 17, $1748-1758$.

Park Y.-S., Kwon Y.-S., Hwang S.-J. and Park S.-K., 2014. Characterizing effects of landscape and morphometric factors on water quality of reservoirs using a self-organizing map. Environ. Model. Softw., 55, 214-221.

Qu X., Song M.-Y., Park Y.-S., Oh Y.N. and Chon T.-S., 2008. Species abundance patterns of benthic macroinvertebrate communities in polluted streams. Ann. Limnol. - Int. J. Lim., 44, 119-133.

Qu X., Zhang H., Zhang M., Liu M., Yu Y., Xie Y. and Peng W., 2016. Application of multiple biological indices for river health assessment in northeastern China. Ann. Limnol. - Int. J. Lim., 52, 75-89.

Schmutz S., Kaufmann M., Vogel B., Jungwirth M. and Muhar S., 2000. A multi-level concept for fish-based, river-type-specific assessment of ecological integrity. Hydrobiologia, 422, 279-289.

Song M.-Y., Lee W.-O., Kim K.-H., Park Y.-S. and Bae M.-J., 2016. The impact of the Goesan dam on fish communities up- and downstream. Ann. Limnol. - Int. J. Lim., 52, 151-162.

Wang C., Liu Y., Li X., Lai Z., Tackx M. and Lek S., 2015. A bibliometric analysis of scientific trends in phytoplankton research. Ann. Limnol. - Int. J. Lim., 51, 249-259. 